\title{
UAV AND MMS - MODERN, REMOTE TECHNOLOGIES, USED COMPLEMENTARY TO THE INVESTIGATION OF THE NATURAL ENVIRONMENT AND THE BUILT SPACE
}

\author{
Mihai Simon ${ }^{1}$, Cosmin Popescu $^{1}$, Loredana Copăcean ${ }^{1}$, Luminița Cojocariu ${ }^{1,2}$ \\ ${ }^{1}$ Banat's University of Agricultural Sciences and Veterinary Medicine \\ „King Mihai I of Romania” from Timişoara, Calea Aradului 119, Timişoara 300645, Romania \\ ${ }^{2}$ Agricultural Research and Development Station Lovrin, Romania
}

\begin{abstract}
The aim of this study was to demonstrate the applicability and opportunity of the means and methods of remote sensing $(M M S)$ and photogrammetry (UAV) in rendering faithfully, with very high accuracy and precision, the components of geographical space, "remotely", without a direct contact with the investigated objective. As a case study, a immobile consisting of a construction and the related agricultural land, located in a rural locality, was chosen. To investigate the targeted immobile, a flight with UAV equipment (DJI Phantom 4RTK) and a "ground" scan with MMS equipment (Leica Pegasus Backpack) was performed. After the acquisition and separate processing, the data obtained through the two technologies (point clouds, orthophotoplans or images), were analyzed and processed in a "combined" way, in this case being obvious their complementarity relationship. As both the drone and the scanner have incorporated GNSS and INS equipment, the data obtained are "in coordinates" and therefore the use of control points and the georeferencing operation is excluded. By combining these "remote" measurements, the detailed topographic survey (with GPS and total station) is replaced and by $3 D$ analysis all the details from the outside, but also from inside the plot are captured. By creating the orthophotoplan, the way of land use, aspects related to vegetation or the way of arrangement can be analyzed. The equipment used and the working methodology "experienced" in this study can be applied in any type of space or for any purpose.
\end{abstract}

Keywords: measurements, overlapping, remote sensing, scan.

\section{INTRODUCTION}

In recent years, the number of sensors and data collection systems has grown considerably. In addition to total stations and GPS systems, the most used topographic equipment, today, there are several options available for data collection, both topographic and for other fields of activity, from several different sources (Chatzistamatis et al., 2018).

Both UAV technology (Unmanned Aerial Vehicle) and MMS (Mobile Mapping System) are techniques with remarkable results in the measurement and mapping activity (Gruen et al., 2013). While UAV technology is constantly evolving, MMS technology is just beginning, especially in Romania, where the number of specific equipment is still very low.

Both internationally and in Romania, data acquired with drones are widely used in agriculture (Stafford, 2002; Zhang and Kovacs, 2012; Rokhmana, 2015; Tripicchio et al., 2015; Mahajan and Bundel, 2017; Puri et al., 2017; Shamshiri et al., 2018; Raparelli and Bajocco, 2019), in 
environmental monitoring, mapping or analysis of the evolution and prediction of phenomena (Sona et al., 2016; Themistocleus, 2017; Cohen et al., 2018; Sanches et al., 2018; Herrmann et al., 2020). In contrast, MMS technology addresses, in particular, the mapping and modeling of different components of geographical space, with remarkable results for architecture, design, geography or geodetic sciences (El-Sheimy and Schwarz, 1998; Pirotti et al., 2013; Guarnieri et al., 2015; Masiero et al., 2017; Nocerino et al., 2017; Simon et al., 2019).

With the help of drones, high quality aerial images can be collected for "modeling" the investigated areas using photogrammetric techniques (Simon et al., 2018). Because the whole process takes place in the air, there are difficulties in acquiring information about objects under trees or under the roofs of houses (Nex and Remondino, 2014). Instead, MMS collects information in the form of point clouds along with stereographic images, by scanning from the ground. Depending on the need, the "range" of the laser can be determined, but it cannot penetrate beyond solid obstacles or into another plane, for example for scanning the roofs of buildings (Tucci et al., 2017). The possibility to combine the data sets obtained by the two technologies, makes them complementary.

The aim of this study was to demonstrate the applicability and appropriateness of the means and methods of remote sensing (MMS) and photogrammetry (UAV) in rendering faithfully, with very high accuracy and precision, the components of geographical space, "remotely", without a direct contact with the investigated objective.

\section{MATERIALS AND METHODS}

As a case study, a building consisting of a construction and the related agricultural land was chosen, located in Seitin locality from the southwest of the Arad Plain, in the Mures meadow.

The working methodology applied in the research involves several steps, summarized in Figure 1.

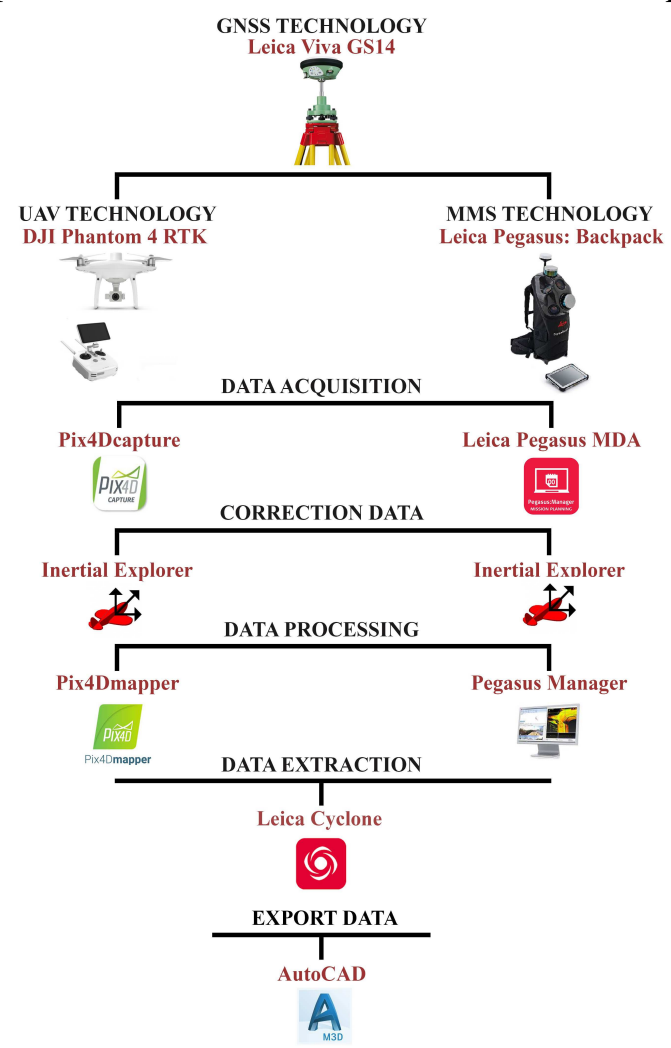

Figure 1. Research methodology 
The equipment and software used according to the technical manuals are presented in Table 1.

Table 1 Software, equipment and means used for data acquisition and processing

\begin{tabular}{|l|}
\hline \multicolumn{1}{|c|}{ Field stage } \\
\hline - Leica Viva GS14 GNSS receiver: used as a Master Base to collect satellite observations at 1Hz \\
throughout the flight and ground scan, data acquired through the Leica SmartWorx application; \\
\hline - DJI Phantom 4 RTK drone: for the acquisition of aerial images with the help of the \\
Pix4Dcapture application; \\
\hline $\begin{array}{l}\text { - Leica Pegasus Backpack mobile scanning system: for collecting point clouds and stereographic } \\
\text { images through the MDA application - Mobile Data Acquisition }\end{array}$ \\
\hline \multicolumn{1}{c|}{ Office stage } \\
\hline $\begin{array}{l}\text { - Inertial Explorer program } \text { - for correcting the trajectory and transforming the coordinates from } \\
\text { the WGS'84 system into the national STEREO'70 system, both for UAV data and for MMS data; }\end{array}$ \\
\hline - Pix4Dmapper program for UAV data processing; \\
\hline - Pegasus Manager program for MMS data processing; \\
\hline - Leica Cyclone program, for extracting and "modeling" information from the point cloud \\
\hline - AutoCAD program - for preparing the final documentation. \\
\hline
\end{tabular}

\section{RESULTS AND DISCUSSIONS}

The methodology for acquiring UAV and MMS data was applied to obtain an extremely detailed and complete digital model (Eisenbeiss and Zhang, 2006). The traditional point cloud derived from terrestrial laser scanning was integrated with data obtained from a UAV photogrammetry campaign (Eltner et al., 2013).

\section{Data acquisition with UAV equipment}

The photogrammetric flight was made with a DJI Phantom 4 RTK drone that includes a Real Time Kinematic module that provides centimeter position information to obtain a very high absolute accuracy of the meta-information in the images.

DJI Phantom 4 RTK is equipped with a DJI FC6310R camera that has a glass lens and not a plastic one, as is the case with DJI Phantom 4 Pro, equipment used in previous research (Simon et al. 2019). However, the camera specifications are identical to the camera on the DJI Phantom 4 Pro. The major difference between the two devices is the RTK module that allows us to acquire images without using ground control points for small areas (Peppa et al., 2019).

To obtain point clouds, in the case of drone flight, the working algorithm described in Figure 1 and Table 1 was applied.

\section{Data acquisition through MMS technology}

The terrestrial scan was performed with a very new equipment that appeared on the Romanian market, namely Leica Pegasus: Backpack. This equipment is the top solution in recording and capturing data about the surrounding reality, indoors, outdoors and underground. This equipment captures and combines image and point cloud data, even in locations where GNSS positioning is missing (Masiero et al., 2017).

Designed to capture the surrounding realities quickly and easily, the Leica Pegasus: Backpack makes progressive scanning a simple procedure. The equipment is a platform for sensors to capture reality. It has an extremely ergonomic design and combines five cameras that offer a fully calibrated 360-degree view and two LiDAR sensors. This unique mobile mapping solution is designed for fast and regular capture of reality (Leica Pegasus Backpack Wearable Mobile Mapping Solution).

Given that the scanning process results in millions of points that represent the exact position of all objects in the scanned area, the scanning process allows a better use of resources because in case of omission of details is not necessary another field visit. 
Current Trends in Natural Sciences

Vol. 9, Issue 17, pp. 117-125, 2020

https://doi.org/10.47068/ctns.2020.v9i17.013

Current Trends in Natural Sciences (on-line)

ISSN: 2284-953X

ISSN-L: 2284-9521
Current Trends in Natural Sciences (CD-Rom)

ISSN: 2284-9521

ISSN-L: 2284-9521

GNSS recordings that took place throughout the flight and scan were made with a Leica Viva GS14 GNSS antenna. This smart antenna is the universal GNSS tool for obtaining professional reliability when we need very high accuracy. The antenna was used as a reference station - Master Base, its location was made in an area without obstacles, with satellite visibility and minimal interference (away from buildings, trees, cars, power lines, etc.). The station collected L1 / L2 observations at 1 $\mathrm{Hz}$ and stored raw RINEX data (.20g, .20o and 20n files). These data were used in post-processing data obtained from photogrammetry and scanning.

\section{Planning the data acquisition mission}

In this study, the data acquisition mission was divided into three stages:

- In the first stage, the reference station was located and configured;

- In the second stage, a planned flight was performed using the Pix4Dcapture application;

- The last stage was mobile scanning, which in turn is divided into five phases:

- static initialization, for 5 minutes; during this time the equipment remained motionless in the position in which it was placed to configure its GNSS Almanac and to establish the position; during this time the parameters for the cameras as well as the distance for the pictures were set;

- dynamic initialization, for 2-3 minutes, during which the equipment was moved continuously to put the GPS / INS system into operation;

- effective scanning; the area of interest is crossed with the equipment mobilized by the operator;

- completion of the process - after taking over the data to complete the whole process in a correct and precise way, the initializations were done again, but this time in reverse order, first the dynamic initialization for 2-3 minutes, then static initialization for 5 minutes.

The whole mission was completed in about 30 minutes, much shorter compared to other technologies in the field. A very large amount of data resulted without affecting the integrity of the scanned objects.

\section{Data processing}

The data were processed in dedicated software, presented in the research methodology and exported in the form of a point cloud in .las files in order to be integrated together.

Due to the GNSS and INS systems integrated in these equipments and the data collected by the reference station, both data sets were obtained in the same coordinate system and with the same precision. The overlap of the two data sets (Figure 2) was done perfectly, without the need to correct any data set. So I got a faithful copy of reality in digital format, without omitting any information.

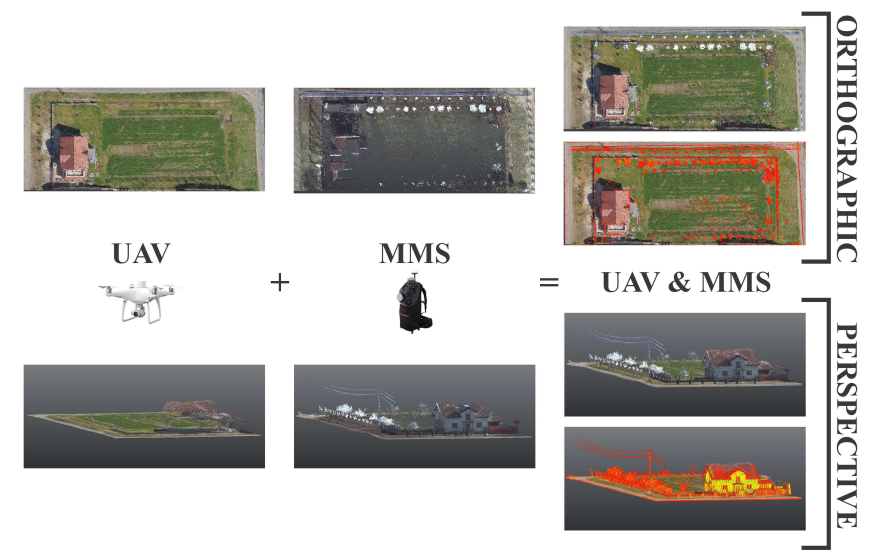

Figure 2. Combining UAV and MMS datasets 


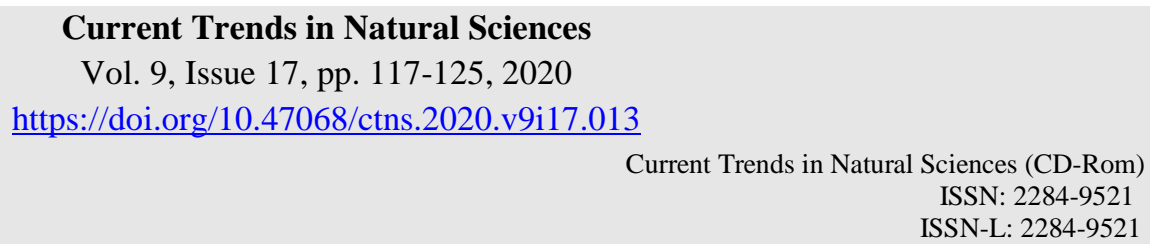

Based on this complex data set, different analyzes can be made, 3D models or 2D plans can be built. For studies on land use, both built space and agricultural land we have developed a Digital Terrain Model (DTM) which is the 3D digital representation of the area. For the realization of this DTM on the whole investigated area, points were automatically placed at the base of the terrain so that the points are not found on the building, vegetation or other high elements. All these points were joined by a network of triangles on the basis of which we obtained the digital model of the terrain. For a better investigation of the area, we also built the level curves (Figure 3).

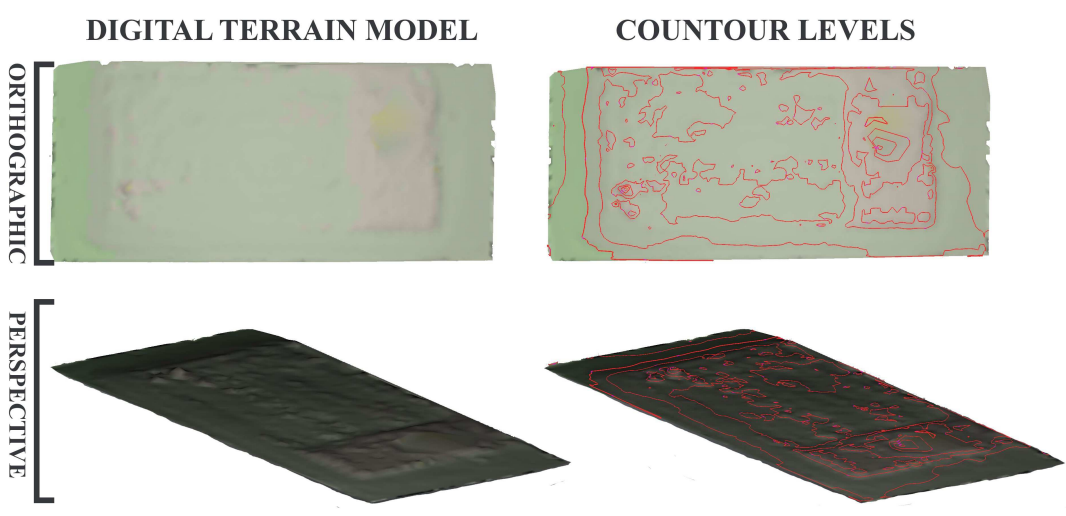

Figure 3. Digital Terrain Model (DTM) and contours

To create a 2D plan it was necessary to prepare the area through horizontal sections at various heights (Figure 4). These sections have the role of eliminating the information we do not need, but they are also useful for determining the ground footprint of the construction and the fence.
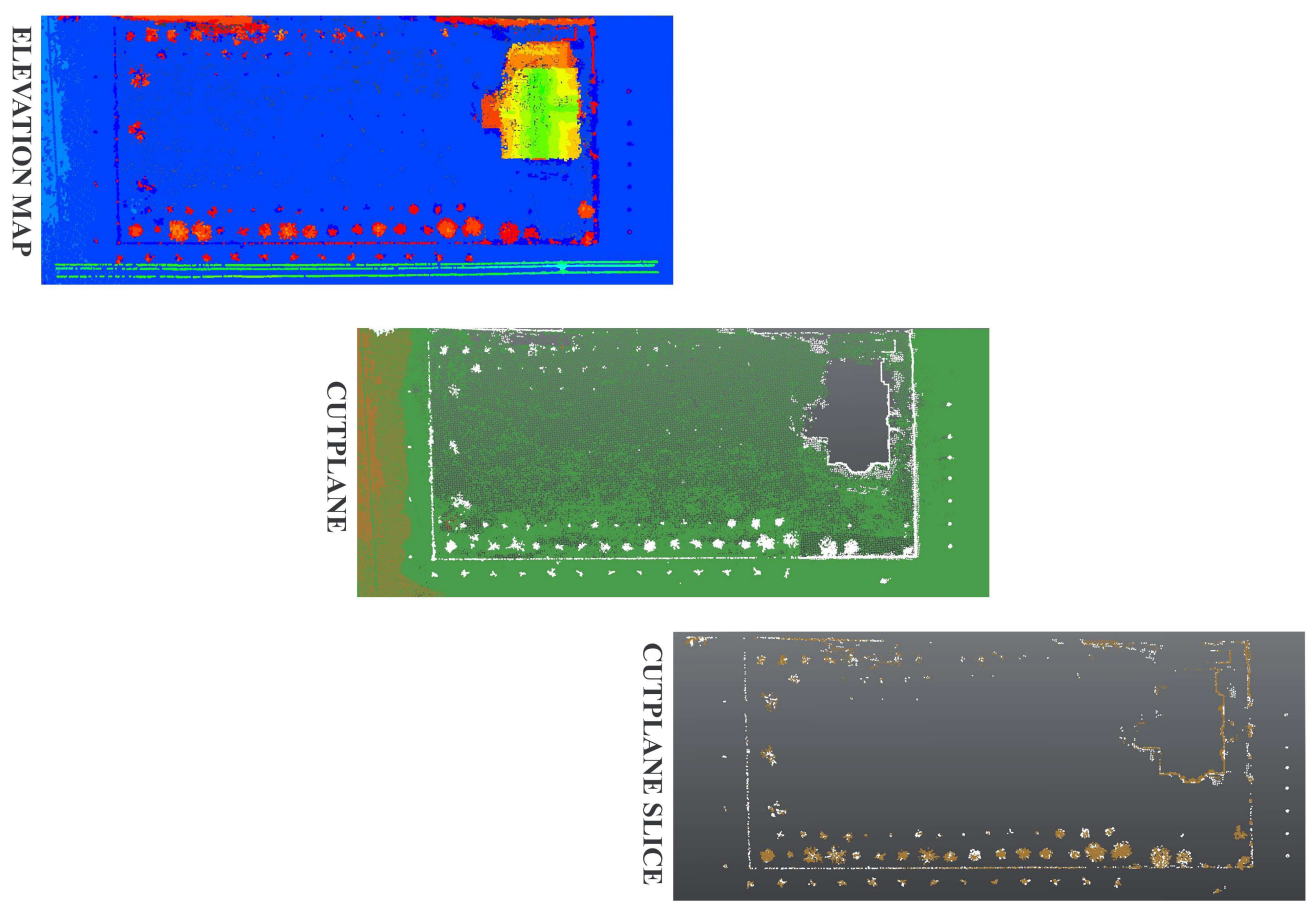

Figure 4. Horizontal sections in the area of interest 


\section{Current Trends in Natural Sciences}

Vol. 9, Issue 17, pp. 117-125, 2020

https://doi.org/10.47068/ctns.2020.v9i17.013

Current Trends in Natural Sciences (on-line)

ISSN: 2284-953X

Current Trends in Natural Sciences (CD-Rom)

ISSN: 2284-9521

ISSN-L: 2284-9521

ISSN-L: 2284-9521

\section{Information extraction and processing}

Once the area is ready, the information is extracted. The advantage of using combined data obtained by UAV and MMS technology is their complementarity. For example: when drawing the ground footprint of the building, very large errors appear from the UAV data because, following the aerial overflight, the projection on the ground is blocked by the roof (Figure 5), but from the data obtained with MMS equipment can be extracted very detailed, from the outside of the building, more precisely everything we can see from the ground. In this way, by using both data sets, the "gaps" are filled in and all the details in the field are captured, regardless of the representation plan.

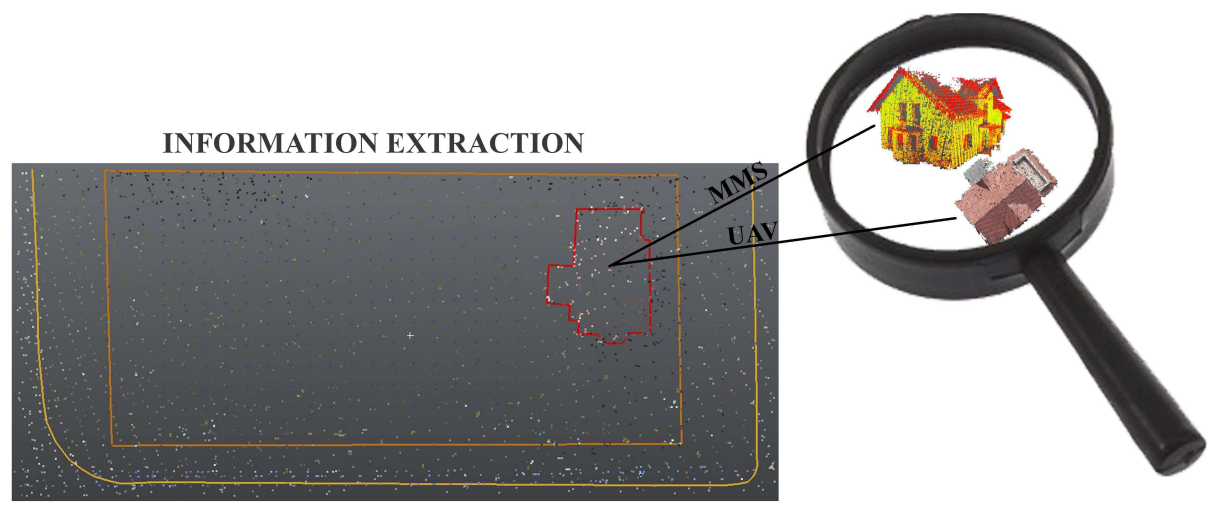

Figure 5. Extracting spatial information

The lack of a compact fence allows the laser to penetrate inside the analyzed perimeter, but the information is incomplete in some places. The combination with the data obtained with the UAV equipment offers us the possibility to complete the data, especially in the areas inside the analyzed perimeter and in the upper part of the construction.

Another objective of the study, achievable by combining the two technologies, UAV and MMS, is to create a situation plan of the studied perimeter, detailed topographic plan, which contains information in the Stereographic 1970 reference system (Figure 6).

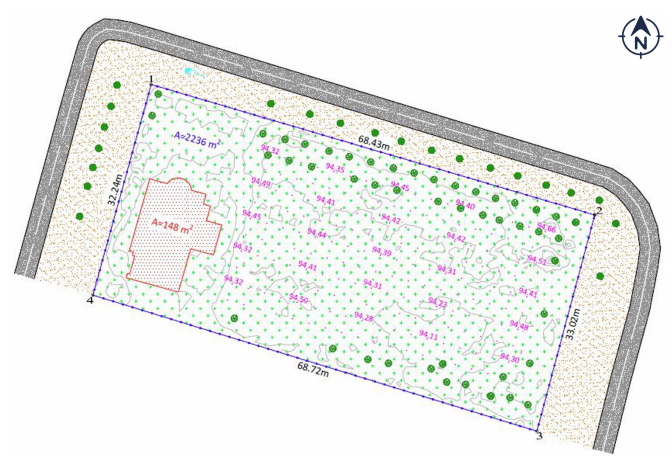

Figure 6. Situation plan represented in $3 D$ and $2 D$

The following information can be extracted from the situation plan:

- length of the fence $-68.43 \mathrm{~m}$ on one side and $68.72 \mathrm{~m}$ on the other side;

- width of the fence - $32.24 \mathrm{~m}$ on one side and $33.02 \mathrm{~m}$ on the other side;

- the surface of the studied area - 2236 sqm;

- the ground surface of the construction - 148 sqm; 


\section{Current Trends in Natural Sciences}

Vol. 9, Issue 17, pp. 117-125, 2020

https://doi.org/10.47068/ctns.2020.v9i17.013

Current Trends in Natural Sciences (on-line)

ISSN: 2284-953X

ISSN-L: 2284-9521
Current Trends in Natural Sciences (CD-Rom)

ISSN: 2284-9521

ISSN-L: 2284-9521

- average land elevation - $94.35 \mathrm{~m}$.

Due to the fact that all the data brought in the 2D plan are in a coordinate system, it can be used in the design and arrangement activity (Figure 7).

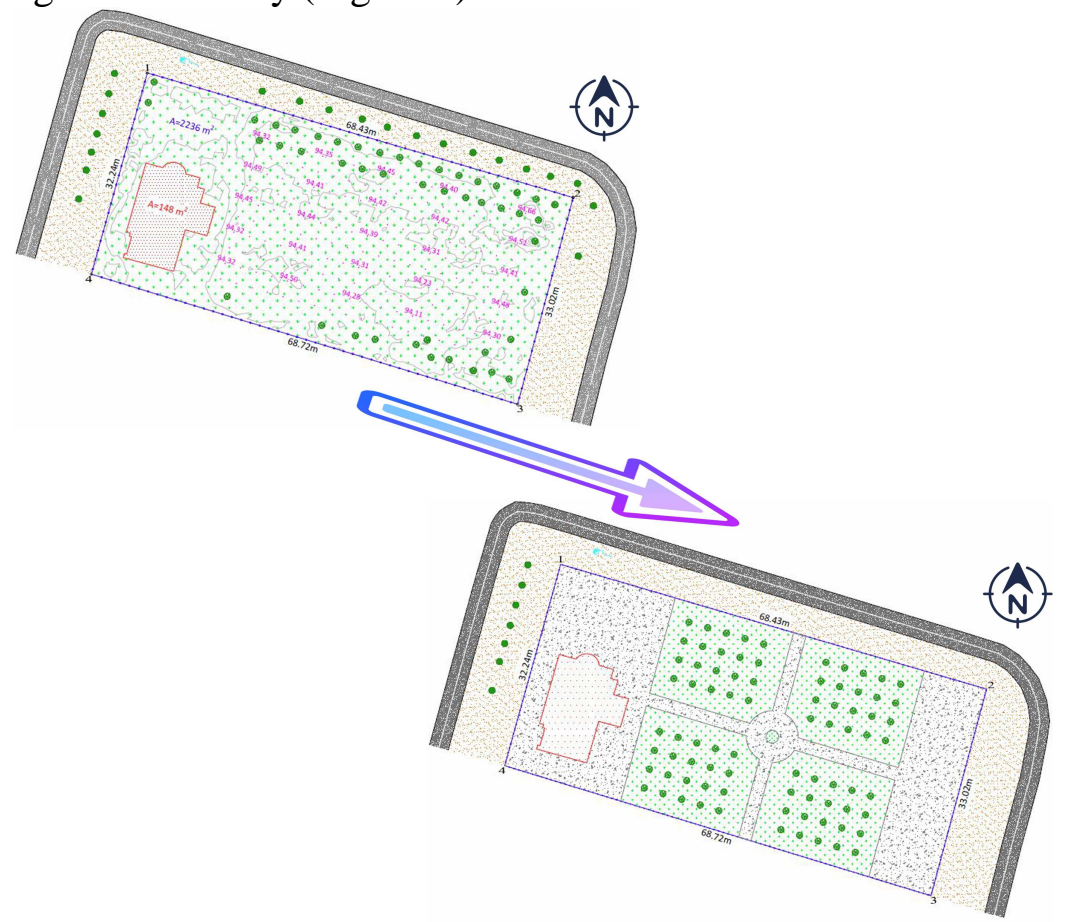

Figure 7. Proposal for landscaping of agricultural areas

The proposed arrangement example can be materialized in the future and aims at planting fruit trees, but also a space for vegetable growing, given the location of the building in the rural area.

\section{CONCLUSIONS}

The results of the study demonstrate the compatibility and complementarity of the data acquired by two means specific to remote sensing and photogrammetry.

By combining the data sets obtained "remotely", by UAV and MMS technology, the topographic survey of detail (with GPS and total station) is replaced, and by 3D analysis all the details from the outside, but also from inside the investigated objective are captured.By creating the orthophotoplan, the way of land use, aspects related to vegetation or the way of arrangement can be analyzed.

As both the drone and the scanner have incorporated GNSS and INS equipment, the data obtained are "coordinated" and therefore the use of control points and georeferencing operation is excluded, which means a significant reduction in working time and operator effort.

The equipment used and the working methodology "experienced" in this study can be applied in any type of space or for any purpose.

\section{REFERENCES}

Chatzistamatis, S., Kalaitzis, P., Chaidas, K., Chatzitheodorou, C., Papadopoulou, E.E., Tataris, G., Soulakellis, N. (2018). Fusion of TLS and UAV photogrammetry data for post-eartquake 3D modeling of a cultural heritage church, The International Archives of the Photogrammetry, Remote Sensing and Spatial Information Sciences, Volume XLII-3/W4, 2018 GeoInformation For Disaster Management (Gi4DM), 18-21 March 2018, Istanbul, Turkey 


\section{Current Trends in Natural Sciences}

Vol. 9, Issue 17, pp. 117-125, 2020

https://doi.org/10.47068/ctns.2020.v9i17.013

Current Trends in Natural Sciences (on-line)

ISSN: 2284-953X

Current Trends in Natural Sciences (CD-Rom)

ISSN: 2284-9521

ISSN-L: 2284-9521

ISSN-L: 2284-9521

Cohen, O., Cartier, A., Ruz, Marie-Hélène (2018). Mapping Coastal Dunes Morphology and Habitats Evolution Using UAV and Ultra-High Spatial Resolution Photogrammetry, International Workshop „Management of coastal dunes and sandy beaches", Dunkirk, 12-14 june 2018

Eisenbeiss, H., Zhang, L. (2006). Comparison of DSMs generated from mini UAV imagery and terrestrial laser scanner in a cultural heritage application, ISPRS Commission V Symposium 'Image Engineering and Vision Metrology', Dresden, Germany, September 25-27, 2006, Volume XXXVI(5), pp: 90-96, https://doi.org/10.3929/ethz-b000158047

El-Sheimy, N., Schwarz, K. (1998). Navigating urban areas by VISAT-A mobile mapping system integrating GPS/INS/digital cameras for GIS applications. Navigation 45(4), pp. 275-285

Eltner, A., Mulsow, C., Mass, H.-G. (2013). Quantitative measurement of soil erosion from TLS and UAV data, International Archives of the Photogrammetry, Remote Sensing and Spatial Information Sciences, Volume XL1/W2, 2013 UAV-g2013, 4 - 6 September 2013, Rostock, Germany

Gruen, A., Huang, X., Qin, R., Du, T., Fang, W., Boavida, J., Oliviera A. (2013). Joint processing of UAV imagery and terrestrial mobile mapping system data for very hing resolution city modeling, International Archives of the Photogrammetry, Remote Sensing and Spatial Information Sciences, Volume XL-1/W2, 2013 UAV-g2013, 4 - 6 September 2013, Rostock, Germany

Guarnieri, A., Masiero, A., Vettore, A., Pirotti, F. (2015). Evaluation of the dynamic processes of a landslide with laser scanners and bayesian methods. Geomatics, Natural Hazards and Risk 6(5-7), pp. 614-634

Herrmann, I., Bdolach, E., Montekyo, Y., Rachmilevitch, S., Townsend, P.A., Karnieli, A. (2020). Assessment of maize yield and phenology by drone-mounted superspectral camera, Precision Agriculture, 21, 51-76. https://doi.org/10.1007/s11119-019-09659-5

Mahajan, U., Bundel, B.R. (2017). Drones for Normalized Difference Vegetation Index (NDVI), to Estimate Crop Health for Precision Agriculture: A Cheaper Alternative for Spatial Satellite Sensors, In Proceedings of the International Conference on Innovative Research in Agriculture, Food Science, Forestry, Horticulture, Aquaculture, Animal Sciences, Biodiversity, Ecological Sciences and Climate Change (AFHABEC-2016). Jawaharlal Nehru University, New Delhi, India: 28-41

Masiero, A., Fissore, F., Guarnieri, A., Piragnolo, M., Vettore, A. (2017). Comparision of low cost photogrammetric survey with TLS and Leica Pegasus Backpack 3D modelss, The International Archives of the Photogrammetry, Remote Sensing and Spatial Information Sciences, Volume XLII-2/W8, 2017, 5th International Workshop LowCost 3D - Sensors, Algorithms, Applications, 28-29 November 2017, Hamburg, Germany

Nex, F., Remondino, F. (2014). UAV for 3D mapping applications: a review. Appl Geomat 6, 1-15 (2014). https://doi.org/10.1007/s12518-013-0120-x

Nocerino, E., Menna, F., Remondino, F., Toschi, I., Rodríguez-Gonzálvez, P. (2017). Investigation of indoor and outdoor performance of two portable mobile mapping systems, Proc. SPIE 10332, Videometrics, Range Imaging, and Applications XIV, 103320I (26 June 2017); https://doi.org/10.1117/12.2270761

Peppa, M., V., Hall, J., Goodyear, J., Mills, J.,P., (2019). Photogrammetric assessment and comparision of DJI Phantom 4 Pro and Phantom 4 RTK small unmanned aircraft systems, The International Archives of the Photogrammetry, Remote Sensing and Spatial Information Sciences, Volume XLII-2/W13, 2019 ISPRS Geospatial Week 2019, 10-14 June 2019, Enschede, The Netherlands

Pirotti, F., Guarnieri, A., Vettore, A. (2013). State of the art of ground and aerial laser scanning technologies for highresolution topography of the earth surface. European Journal of Remote Sensing 46, pp. 66-78

Puri, V., Nayyar, A., Raja, L. (2017). Agriculture drones: A modern breakthrough in precision agriculture, Journal of Statistics and Management Systems, 20 (4): 507-518. doi.org/10.1080/09720510.2017.1395171

Raparelli, E., Bajocco, S. (2019). A bibliometric analysis on the use of unmanned aerial vehicles in agricultural and forestry studies, International Journal of Remote Sensing, 40 (24): 9070-9083, doi.org/10.1080/01431161.2019.1569793

Rokhmana, C.A. (2015). The Potential of UAV-based Remote Sensing for Supporting Precision Agriculture in Indonesia, Procedia Environmental Sciences 24: 245-253. doi:10.1016/j.proenv.2015.03.032

Sanches, G.M., Duft, D.G., Kölln, O.T., Dos Santos Luciano, A.C., Quassi De Castro, S.G., Okuno, F.M., Junqueira Franco, H.C. (2018). The Potential for RGB Images Obtained Using Unmanned Aerial Vehicle to Assess and Predict Yield in Sugarcane Fields, International Journal of Remote Sensing 39 (15-16): 5402-5414. doi:10.1080/01431161.2018.1448484

http://www.natsci.upit.ro

*Corresponding author, E-mail address: lorecopacean@yahoo.com 


\section{Current Trends in Natural Sciences}

Vol. 9, Issue 17, pp. 117-125, 2020

https://doi.org/10.47068/ctns.2020.v9i17.013

Current Trends in Natural Sciences (on-line)

ISSN: 2284-953X

Current Trends in Natural Sciences (CD-Rom)

ISSN: 2284-9521

ISSN-L: 2284-9521 ISSN-L: 2284-9521

Shamshiri, R.R., Weltzien, C., Hameed, I.A., Yule, I.J., Grift, T.E., Balasundram, S.K., Pitonakova, L., Ahmad, D., Chowdhary, G. (2018). Research and Development in Agricultural Robotics: A Perspective of Digital Farming, International Journal of Agricultural and Biological Engineering 11 (4): 1-14, doi:10.25165/j.ijabe.20181104.4278

Simon, M., Copacean, L., Cojocariu, L. (2018). U.A.V. technology for the detection of spatio-temporal changes of the useful area for forage of grassland. Research Journal of Agricultural Science, 50 (4), pp: 332-341, Timisoara, Romania

Simon, M., Copacean, L., Cojocariu, L. (2019). Viewing data sets produced by photogrammetry in web browsers. Applications on grasslands in Arad county, Research Journal of Agricultural Science, 51 (3), pp: 133 - 142, Timisoara, Romania

Sona, G., Passonia, D., Pinto, L., Pagliari, D., Masseroni, D., Ortuani, B., Facchi, A. (2016). UAV Multispectral Survey to Map Soil and Crop for Precision Farming Applications, The International Archives of the Photogrammetry, Remote Sensing and Spatial Information Sciences, 41: 1023-1029. https://doi.org/10.5194/isprs-archives-XLIB1-1023-2016

Stafford, J.V. (2002). Implementing Precision Agriculture in the 21st Century, Journal of Agricultural Engineering Research 76 (3): 267-275. doi:10.1006/jaer.2000.057

Themistocleus, K. (2017). The use of UAVs for monitoring land degradation, Earth Resources and Environmental Remote Sensing/GIS Applications VIII, edited by Michel., U., Schultz K., Proceedings of SPIE Remote Sensing, Volume 10428,104280E-1; doi: 10.1117/12.2279512

Tripicchio, P., Satler, M., Dabisias, G., Ruffaldi, E., Avizzano, C.A. (2015). Towards smart farming and sustainable agriculture with drones, In Proceedings of the 2015 International Conference on Intelligent Environments, Prague, 15-17 July 2015: 140-143. DOI: 10.1109/IE.2015.29

Tucci, G., Bonora, V., Conti, A., Fiorini, L. (2017). Digital workflow for the acquisition and elaboration of 3D data in a monumental complex: The fortress of Saint John the Baptist in Florence, The International Archives of the Photogrammetry, Remote Sensing and Spatial Information Sciences, Volume XLII-2/W5, 2017, 26th International CIPA Symposium 2017, 28 August-01 September 2017, Ottawa, Canada

Zhang, C., Kovacs, J.M. (2012). The application of small unmanned aerial systems for precision agriculture: a review, Precision Agriculture 13: 693-712. doi:10.1007/s11119-012-9274-5

•. Agisoft PhotoScan User Manual Professional Edition, Version 1.4, https://www.agisoft.com/pdf/photoscanpro_1_4_en.pdf accessed in 15.02.2020

•.• Leica Cyclone Model Documentation - https://leica-geosystems.com/products/laser-scanners/software/leicacyclone/leica-cyclone-model accessed in 14.02.2020

•.• Leica Pegasus:Backpack Wearable Mobile Mapping Solution - https://leica-geosystems.com/products/mobilesensor-platforms/capture-platforms/leica-pegasus-backpack

•• User Manuale Pix4Dcapture https://support.pix4d.com/hc/en-us/sections/200733429-Getting-Started-User-ManualsSpecial-Install accessed in 15.02.2020 